\title{
The Study of the Relationship between Parsian Bank's Knowledge Management and its Financial Performance
}

\author{
Ali Jamshidi ${ }^{1}$, Omid Grey ${ }^{2, *}$ \\ ${ }^{1}$ Assistant professor, Department of Management, Payame Noor University, \\ PO BOX 19395 - 3697, Tehran, IRAN \\ ${ }^{2}$ Department of Management, Payame Noor University, PO BOX 19395 - 3697, Tehran, IRAN \\ o.geray@iiees.ac.ir
}

\begin{abstract}
Keywords: Knowledge Management Strategies, Knowledge Management Processes, Commercial Strategy, Individual Knowledge.
\end{abstract}

\begin{abstract}
Present research's goal is to study the relationship between knowledge management of Parsian Bank and its financial performance. The statistical population consists of 220 executives, assistants and postgraduate staff in banking and financial management. The statistical sample consists of 144 of them who were determined according to the Morgan Table. This research uses quantitative and survey method and it has a practical purpose. The results show that there is a meaningful relationship between the research variables and that the relationship between them includes strength and weakness.
\end{abstract}

\section{Introduction}

To answer why organizational knowledge is an asset and why it is important for business, it can be argued that success in correct and practical implementation of knowledge management empowers an organization with increasingly more intelligent decision-making ability, more accurately targeted competition in the business field, and increased focus on quality outputs. Utilization of the knowledge management instruments in an organization causes data to be managed and distributed substantively and logically, resulting in more useful and effective information for the organization. One type of knowledge acquired by organizations is tacit knowledge. This sort of knowledge is exclusively at the possession of an individual and the organization only benefits from such knowledge for as long as that individual is employed at the organization. Tacit knowledge is lost when the personnel leave the organization, or at the best case scenario, it is transferred to the competition. Generally, tacit knowledge is not systemized and there are no mechanisms for its control. In any organization, recording, sharing and preservation of tacit knowledge transform it into explicit knowledge and could noticeably decrease the cost of reacquiring such knowledge and experience.

One sample of acquired knowledge in organizations is the important information obtained from research and development section of manufacturing companies. In most manufacturing firms, largest investment is in this section, because in long term, research and development could result in manufacturing a product that will determine the company's survival or its elimination from the field of competition. Research shows that sustainability and durability of knowledge in an organization are by far longer lasting than a manufactured product, and this is another proof of importance of preservation and sharing of knowledge in an organization.

Business strategy, asset management strategy, individual knowledge, knowledge creation strategy, and knowledge transfer strategy of service organizations such as banks, like that of manufacturing firms, are faced with increasing competition. Banks should be able to preserve their current customers and attract new ones by meeting their customers' increased and elevated demands [1]. The main point of this research is to determine what relationship Parsian Bank's knowledgebased strategies have with its performance. 


\section{The Significance and Necessity of the Research}

Most of today's big banks have realized that they will be successful because of the skills and experiences of their work force and not because of physical and mechanical systems, and that if they cannot elevate the scientific and expertise level of their work force they will definitely be pushed out of the global market. Noting that with private banks competition is of prime significance, discussion of knowledge management as the primary factor in gaining competitive advantage has been considered the most. However, in governmental institutions, considering the irrelevance of competition within them, not much attention has been paid to the subject of knowledge management. However, considering the advancement of the banking systems in other countries and the international communication between the world's banks, which is also referred to as globalization of trade and communication, will cause the banking system in the country to unwillingly move towards knowledge-based banking interactions [1]. Every day, managers are bombarded with almost similar information. According to David Derbyshire "Scientist have accurately calculated how much data is sent for a particular individual in the course of a year, for each person in the world this amount equals to reading 174 newspapers each day".

This bombardment of data has caused knowledge management to become increasingly important. There are three main reasons why knowledge management is important for a company's success:

1) It facilitates the decision-making process.

2) It accustoms organizations to learning on a regular basis.

3) It encourages cultural changes and innovation in an organization.

Data is capable of providing a lot of information to managers, but processing such large amount of data prevents high quality decisions. Executive Council of CEC GE Company is an example of how firms, by implementing a knowledge management system, helps executive officers to omit unnecessary information, share information and improve decision-making. CEC, which is comprised of managers from fourteen important businesses, has two-day sessions, gatherings for sharing the best actions taken, accelerating improvements and discussions relating to success, failure and experience. While information bombardment or the need for other individuals' knowledge could cause difficulties and problems for the managers, establishing a knowledge management system can improve performance and generate well-informed decisions [3].

\section{Subject Terminology}

Knowledge is information part of data that is rooted in knowing and awareness. Another meaning of knowledge is comprehension and recognition that is acquired during study, research or observation.

Knowledge is a valuable resource for empowering organization in innovation and competition. Such knowledge could result in well-informed employees. In fact, the process of knowledge management is the creation of a system in an organization that systematizes the knowledge related work. To transform knowledge into a capital good, organizations must make an effort to create a balance between knowledge management activities. The process of knowledge management can result in creation, dissemination and implementation of knowledge in an organization. In fact, the final goal of knowledge management is to increase intelligence and escalate the intelligence-derived benefits of an organization. In knowledge-oriented organizations, knowledge is easily transferred and provided to employees. When the employees have access to organizational knowledge, they can understand their environment and realize its purpose. They are able to find new and better methods utilizing their expertise, make it meaningful and quantify so that by its implementation, the productivity level of the organization can also increase.

Therefore, from the above description, we can give the following definition for knowledge management: The process, creation, dissemination and implementation of knowledge for the purpose of reaching organizational goals. We live in an era that knowledge is power and knowledge assets act as instruments of power. Knowledge management's duty is managing knowledge assets of an 
organization that must go through a process to reach its goals. Humanity, in its path of evolutionary history and social evolution, has been able to create knowledge and use it to bring changes in the society.

In the $21^{\text {st }}$ century, knowledge-oriented and knowledge-generating organizations are the custodians of knowledge management. Perhaps Alvin Toffler's definition of knowledge can help in better understanding of knowledge management. In this regard, he says: "People do not manage knowledge; knowledge manages people [4].

\section{Knowledge Characteristics}

Knowledge can take shape in two forms, tacit knowledge and explicit knowledge. Explicit knowledge is without ambiguity, clear and obvious; tacit knowledge is an inconspicuous knowledge that exists within an individual. Both kinds of knowledge have characteristics that are as follows:

1 - Knowledge is the result of human activity.

2- Knowledge is the result of thinking.

3- Knowledge is exudation of thought

4- Knowledge is the result of collective intellect.

5- New knowledge is created on the basis of old knowledge [5].

\section{Knowledge Management in Organizations}

There are some reasons for organizations to be inclined to implement knowledge management. Emphasis of organizations is on the manner of job performance and individuals' skills and experiences. Moreover, researchers believe that knowledge plays an effective role in development and by using effective knowledge management; organizations are able to offer better services. If there is only spreading of information within an organization, there would be no increase of knowledge. Finding possessors of knowledge within an organization requires a time process. What the knowledge management system does is establishing communication between individuals to think together and allocate time for sharing thoughts and outlooks that seem appropriate for other members of the group. Use of thinking centers, think tanks or reflection and recording experiences are some tactics for knowledge management [6].

\section{Obstacles to creating knowledge management in organizations}

There are also limitations for implementing knowledge management strategy in organizations, some of which is as follows:

1- Inadequacy of human relations in the knowledge management process.

2- Shortage of expert and elite workforce.

3- Lack of comprehensive value and efforts in knowledge management.

4- Lack of developing a culture for management and dissemination of knowledge within organizations.

5- Lack of clarity regarding the value of knowledge and knowledge management in an organization [7].

\section{Stages of implementation and operationalizing knowledge management in organizations}

To have a knowledge-based or knowledge-driven organization, there are different stages that should be implemented:

1- Teaching concepts and drawing managers' attention to the importance of knowledge in an organization.

2- Evaluation of an organization's knowledge (benchmark survey)

3- Organizing scientific committee knowledge team, thinking room centers, recording reflection and experience or supporting individuals' tacit knowledge.

4- Composing the knowledge outlook (knowledge roadmap).

5- Building a culture of independence for the knowledge management unit in the organization. 
Knowledge management and information technology and implementation of information technology for organizing and sharing knowledge is important to organizations so that by knowledge management strategies they can distinguish themselves, but the impact of strategies on the processes of knowledge management in each organization is not clear. Although there is consensus on importance of the effect that knowledge management strategies have on knowledge management processes, there are few suggestions and opinions concerning selection and the impact of such strategies on knowledge management processes within organizations?

Various researches have introduced and categorized different kinds of knowledge management strategies that an organization might adopt. The most important knowledge management strategies are categorized based on the perspective of focus on knowledge management. From the perspective of focus, system-based strategies and human-based strategies are put forward based on explicit knowledge and tacit knowledge respectively. In system-based strategy, the purpose of documenting and storage of organizational data is to access, reuse and share it [8].

\section{Knowledge management processes}

Knowledge management processes are observable organizational activities dependent on knowledge management. The most common knowledge management processes deal with relative implementation of knowledge storage; the goal of these processes is to acquire knowledge for facilitating broader access by others in similar organization. Creating, acquiring and sharing knowledge are the most relevant knowledge management process [9].

\section{Relationship between knowledge management strategies and knowledge management processes}

Knowledge management strategies design knowledge management process needed for effective management of knowledge; without a distinctive strategy, knowledge management processes can seldom be judged. Suitability of knowledge management processes and knowledge management strategies are essential parts of organizational performance improvement. Some researchers have studied the effect of knowledge management strategies on creation and sharing processes of knowledge [9]. Knowledge management and organizational performance are essential of the success in business. The different results in literatures that declare $\mathrm{KM}$ affects organizational performance positively. In Darroch research, the results support some KM process positively affects performance. She claims that knowledge acquisition doesn't positively affect performance directly, and knowledge dissemination doesn't positively affect performance, either [10]. Knowledge management processes include several stages to develop the organization's ability to obtain and share knowledge and benefit from it in order to survive and succeed, and this means that the organization owning the systems, structures and organizational values and processes that support knowledge management. Knowledge management is "a systematic and integrative process of coordinating organization-wide in pursuit of major organizational goals" [11]. Scholars generally agree that knowledge management processes need to fit with organizational context in order to create a competitive edge [12].

\section{Improvement in Parsian Bank's currency performance after JCPOA ${ }^{1}$}

During the past year, Parsian Bank has faced three significant events including taking responsibility of paying back the deposits of Samen'ol Hojaj Credit Cooperative's investors, commissioning of the branch-system design program titled Lotus at the end of 2015 and implementation of JCPOA. Despite this, the Bank's increased ability in the international and currency sector, expansion of currency activities, and most number of brokerages and dealings with foreign banks among the nation's banks, have created considerable capacity and opportunity for increasing international and currency activities, earnings and profit for Parsian Bank in the currency exchange sector. Parsian Bank is ranked first in the stock market in terms of the number of shareholders [13].

\footnotetext{
${ }^{1}$ Joint Comprehensive Plan of Action
} 


\section{History of previous research}

Bakhtiari with regard to the subject of "importance and necessity of knowledge management in the age of information" demonstrated that in recent years knowledge management has become a significant and vital subject. Both scientific and business communities believe that with the power of knowledge, organizations are able to preserve their long-term advantages in competition. In addition, in their research, scientists have found out that unlike other managements, knowledge management is not short-lived. Rather it has lasting effects. Competitive conditions and environment of organizations are complicated more than ever and are rapidly changing in such a way that the pace of change in most of the organizations is by far greater than their ability to respond and adapt. Constant changes of knowledge also have created a new unstable situation for organizations. In this settings, only those organizations can survive that can maintain their competitive advantage. Pundits of this field believe preservation of an organization's competitive advantage and survivals are possible with the aid of knowledge management, in a way that could constantly generate new knowledge in the organization. In this article history of knowledge management, definition and various categories of knowledge are presented and the concept of knowledge management will be discussed. Then in the proceedings the resulting crisis from lack of knowledge management (or unorganized knowledge) will be put forward and at the end, samples of successful commissioning of knowledge management in organizations will be mentioned [8]. The results of Ra'ed Masa'deh et al research with title The impact of knowledge management on job performance in higher education: The case of the University of Jordan showed that Knowledge management is effective on job performance in higher education [14]. The results of Al-Shourah et al research with title The Knowledge Management Processes and Its Role in Improving Organizational Effectiveness: A Field Study Jordanian Commercial Banks showed that there's an effect for the knowledge management processes and its role in improving organizational effectiveness at Jordanian commercial banks. There are statistically significant differences between knowledge management on improving organizational effectiveness according to experience, but there are no differences to functions. The results also suggest that knowledge management fully referee the impact of organizational effectiveness [10].

\section{Methodology}

In the documentary section of this research, data was collected by library and documentary methods using index cards; in the field and survey section, data was collected using (verified) questionnaires.

This research is of the descriptive and field type and field and survey were chosen as its research method. Verified questionnaire was used to collect the quantitative data of the research, because this method is the most appropriate method for collecting raw data. Then, using quantitative data, hypotheses of the research were examined.

\section{Implementation method}

With the goal of attaining a deeper understanding of the bank's circumstances, the opinions of nine of Parsian Bank's executives were collected using interviews with specific format, which determined content analysis and qualitative data coding resulting from the interviews. The subjects posed in the interviews were used in designing the questionnaires. Since the focus of this article is on the quantitative section of the research, details of the qualitative section were not included.

At the first stage, to examine the validity of the questionnaires and for the purpose of performing a pretest, using questionnaires without a title and without giving bias to the respondents, the clarity of questions was examined. The questionnaires were given in person (with one exception) to twenty one employees of the Parsian Bank as a pilot team who at least held or hold the managing post of a fund and credit section. Based on the feedbacks and the results gathered from the suggestions, the questionnaires were evaluated for face validity, content validity and criterion validity concurrently. This evaluation resulted in some revisions in the introductory text and the questions of the questionnaire to facilitate understanding. At the next stage, a multiple-section questionnaire was 
created with each section having five-choice questions from "very low" to "very high" according to the Likert Scale. At the trial stage, the questionnaires were handed out in person to 144 employees of the Parsian Bank with banking, financial management and accounting education background and their opinions about the questions were collected. After summing up the opinions and reliability assessment, some questions and reliability were omitted. To examine the internal consistency, the amount of Cronbach's $\alpha$ and the general correlation of all the factors are studied. Cronbach's Coefficient Alpha is the most common way to estimate internal consistency. In social sciences, Cronbach's $\alpha$ greater in the amount of 0.6 is acceptable for all latent variables.

\section{Sample specifications}

Statistical population was 220 individuals, 144 of them were chosen as statistical sample according to the Morgan Table; questionnaires were sent to all employees and executives at the Parsian Bank. In this research, employees and executives with majors related to banking, financial affairs and accounting were selected as the target population in Parsian bank. Because it seems that such individuals' knowledge activities have greater effect in the bank. Characteristics of the responders were examined separately by age, employment history, scientific rank, alma mater and gender. Majority of the responders were between the ages of 18 to 45 and were employed between 1 to 25 years.

\section{Results}

\section{Correlation analysis}

The wanted data was obtained using SPSS software to analyze the statistical data. In this research, observed minimum of Cronbach's $\alpha$ variables is 0.72 and the minimum amount of general correlation of the observed variables is 0.48 . This shows that the variables have internal consistency and therefore the questionnaire's internal consistency and reliability is confirmed.

\section{Variables of the research}

Independent Variable:

In this research, knowledge management factors are the independent variable.

Dependent variable:

In this research, Parsian Bank's performance is the dependent variable.

\section{Findings obtained by hypotheses testing}

Testing the first hypothesis: there is a correlation between Parsian Bank's implementation of knowledge transfer strategy and its performance.

Null hypothesis (H0): there is no correlation between implementation of knowledge transfer strategy in Parsian Bank and its performance.

Research hypothesis (H1): there is a correlation between implementation of knowledge transfer strategy in Parsian Bank and its performance.

Table 1. Testing the first hypothesis.

\begin{tabular}{|c|c|c|c|}
\hline & Observed & Expected & Deviation \\
\hline Mean & 99 & 72.0 & 27.0 \\
\hline High & 45 & 72.0 & -27.0 \\
\hline Total & 144 & & \\
\hline \multicolumn{3}{|c|}{ Chi-Square } & $20.250^{\mathrm{a}}$ \\
\hline \multicolumn{3}{|l|}{$\mathrm{df}$} & 1 \\
\hline \multicolumn{3}{|c|}{ Asymp. Sig. } & .000 \\
\hline
\end{tabular}


As seen, testing is done at 5 percent error level and considering the computed error by the SPSS software, it is less than 5 percent. Thus, the null hypothesis indicating no impact from the independent variable on the dependent variable is rejected and the research hypothesis is confirmed. Therefore, it can be said with 95 percent certainty that there is a correlation between Parsian Bank's implementation of knowledge transfer strategy and its performance. Considering the contingency coefficient, the degree of this correlation is average.

Testing the second hypothesis: there is a relationship between Parsian Bank's knowledge creation and its performance.

Null hypothesis (H0): there is no correlation between Parsian Bank's knowledge creation strategy and its performance.

Research hypothesis (H1): there is a correlation between Parsian Bank's knowledge creation strategy and its performance.

Table 2. Testing the second hypothesis.

\begin{tabular}{|l|l|l|l|}
\hline & Observed & Expected & deviation \\
\hline Mean & 54 & 48.0 & 6.0 \\
\hline High & 76 & 48.0 & 28.0 \\
\hline Very high & 14 & 48.0 & -34.0 \\
\hline total & \multicolumn{2}{l|}{} \\
\hline Chi-Square & 144 & 41 & \\
\hline df & 2 & .000 \\
\hline Asymp. Sig. & \multicolumn{2}{l|}{} \\
\hline $\mathrm{c}=\sqrt{(41 /(41+144))=47=\text { contingency coefficient }}$ & \\
\hline
\end{tabular}

As seen, testing is done at 5 percent error level and considering the computed error by the SPSS software, it is less than 5 percent. Thus, the null hypothesis indicating no impact from the independent variable on the dependent variable is rejected and the research hypothesis is confirmed. Therefore, it can be said with 95 percent certainty that there is a correlation between Parsian Bank's implementation of knowledge creation strategy and its performance. Considering the contingency coefficient, the degree of this correlation is relatively strong.

Testing the third hypothesis: there is a correlation between implementation of individual knowledge strategy in Parsian Bank and its performance.

Null hypothesis (H0): there is no correlation between implementation of individual knowledge strategy in Parsian Bank and its performance.

Research hypothesis (H1): there is a correlation between implementation of individual knowledge strategy in Parsian Bank and its performance.

Table 3. Testing the third hypothesis.

\begin{tabular}{|l|l|l|l|}
\hline & Observed & Expected & Deviation \\
\hline Low & 28 & 48.0 & -20.0 \\
\hline Mean & 103 & 48.0 & 55.0 \\
\hline High & 13 & 48.0 & -35.0 \\
\hline Total & 144 & & \\
\hline Chi-Square & & 97 \\
\hline df & 2 & \\
\hline Asymp. Sig. & \multicolumn{2}{l|}{} \\
\hline $\mathrm{c}=\sqrt{(97 /(97+144))=63=\text { contingency coefficient }}$ \\
\hline
\end{tabular}


As seen, testing is done at 5 percent error level and considering the computed error by the SPSS software, it is less than 5 percent. Thus, the null hypothesis indicating no impact from the independent variable on the dependent variable is rejected and the research hypothesis is confirmed. Therefore, it can be said with 95 percent certainty that there is a correlation between Parsian Bank's implementation of individual knowledge strategy and its performance. Considering the contingency coefficient, the degree of this correlation is relatively average.

Testing of the fourth hypothesis: there is a correlation between implementation of knowledge asset management strategy in Parsian Bank and its performance.

Null hypothesis (H0): there is no correlation between implementation of knowledge asset management strategy in Parsian Bank and its performance.

Table 4. Testing the fourth hypothesis.

\begin{tabular}{|c|c|c|c|c|}
\hline & Observed & Expected & & Deviation \\
\hline Low & 51 & 72.0 & & -21.0 \\
\hline Mean & 93 & 72.0 & & 21.0 \\
\hline Total & 144 & & & \\
\hline \multicolumn{3}{|l|}{ Chi-Square } & \multicolumn{2}{|l|}{12} \\
\hline \multicolumn{3}{|c|}{$\mathrm{df}$} & \multicolumn{2}{|l|}{1} \\
\hline \multicolumn{3}{|l|}{ Asymp. Sig. } & \multicolumn{2}{|l|}{.000} \\
\hline \multicolumn{5}{|c|}{$\mathrm{c}=\sqrt{ }(12 /(12+144))=28=$ contingency coefficient } \\
\hline
\end{tabular}

Research hypothesis (H1): there is a correlation between implementation of knowledge asset management strategy in Parsian Bank and its performance.

As seen, testing is done at 5 percent error level and considering the computed error by the SPSS software, it is less than 5 percent. Thus, the null hypothesis indicating no impact from the independent variable on the dependent variable is rejected and the research hypothesis is confirmed. Therefore, it can be said with 95 percent certainty that there is a correlation between Parsian Bank's implementation of knowledge asset management strategy and its performance. Considering the contingency coefficient, the degree of this correlation is average.

Testing the fifth hypothesis: there is a correlation between implementation of business strategy in Parsian Bank and its performance.

Null hypothesis (H0): there is no correlation between implementation of business strategy in Parsian Bank and its performance.

Research hypothesis (H1): there is a correlation between implementation of business strategy in Parsian Bank and its performance.

Table 5. Testing the fifth hypothesis.

\begin{tabular}{|l|l|l|l|}
\hline & Observed & Expected & Deviation \\
\hline Very low & 67 & 48.0 & 19.0 \\
\hline Low & 59 & 48.0 & 11.0 \\
\hline Mean & 18 & 48.0 & -30.0 \\
\hline Total & 144 & & \\
\hline Chi-Square & \multicolumn{2}{l|}{} \\
\hline df & \multicolumn{2}{l|}{} \\
\hline Asymp. Sig. & \multicolumn{2}{|l}{} \\
\hline $\mathrm{c}=\sqrt{(29 /(29+144))=41=\text { contingency coefficient }}$ & 29 & \\
\hline
\end{tabular}


As seen, testing is done at 5 percent error level and considering the computed error by the SPSS software, it is less than 5 percent. Thus, the null hypothesis indicating no impact from the independent variable on the dependent variable is rejected and the research hypothesis is confirmed. Therefore, it can be said with 95 percent certainty that there is a correlation between Parsian Bank's implementation of business strategy and its performance. Considering the contingency correlation, the degree of this correlation is lower than average.

\section{Conclusion}

Knowledge management is favored as a common expression in organizations, in which there is an emphasis on acquiring knowledge about organization's customers, competitors and products from the employees. Being knowledge-based is one of organizational strategies in the current era. Organizations that are inclined toward knowledge management and becoming knowledge-based could become effective in today's competitive world and gain their customer's satisfaction. One type of organizations that are faced with many competitors is banks. Parsian Bank's first place in the stock market, as acknowledged by the majority of its executives and employees, is owed to its presence in the field of knowledge. As stated, this research examined the relationship between Parsian Bank's knowledge management and its performance, and ultimately it was determined that there is a meaningful correlation between the research variables. This correlation was assessed to be average in the first and fourth hypothesis, relatively strong in the second hypothesis, relatively average in the third hypothesis and lower than average in the fifth hypothesis.

\section{References}

[1] M.S. Olia, A. Akhavan, Effect of knowledge management strategies on knowledge management processes in Iranian state universities, Management Sciences of Iran Quarterly. 8(31) (2013) 79-88.

[2] V. Dini, Knowledge management and significance of its necessity in state organizations, Electricity Industry Monthly. 143: 169-183.

[3] M. Mohammadi, Why is knowledge management is important for your company?, Marketing \& Counseling Services Journal. 3 (2014) 1-12.

[4] A. Baha, Organizational leaders, the key to institutionalizing knowledge management in an organization, Management \& Human Resource Journal. 25 (2012) 18-24.

[5] V. Alipour, Knowledge management, definition and concept, Media Research \& Study Center site (Hamshahri), 2012.

[6] M. Norouzi, Application of knowledge management in the state-owned sector, Tadbir Monthly. 156 (2005) 40-51.

[7] H. Adab, M. Shafikhani, To excel utilizing knowledge management, Tadbir Monthly Periodical. 182 (2007) 65-72.

[8] H. Bakhtiari, Research plan: Necessity and importance of knowledge management in the information era, Cultural and Intellectual Research Center, 2009.

[9] N. Rahimian, Guide to reporting in operational auditing”, Auditor Magazine. 16(71) (2014) 112-130.

[10] A.A. Al-Shourah, H. Jazz'a Irtaimeh, K.M. Al-Shawabakeh, The Knowledge Management Processes and Its Role in Improving Organizational Effectiveness: A Field Study Jordanian Commercial Banks, International Journal of Advances in Management and Economics. 3(6) (2018) 78-87. 
[11] P.N. Rastogi, Knowledge management and intellectual capital - the new virtuous reality, Human Systems Management. 19(1) (2000) 39-48.

[12] T.H. Davenport, L. Prusak, Working knowledge: how organizations manage what they effectiveness and organisational effectiveness", Published doctoral thesis, University of Minnesota, USA, (1998).

[13] J. Parvizian, The role of mediators in the electronic distribution system: dynamic systematic approach in Iran. Economy \& New Business Publication, spring edition. 64 (2012) 8-17.

[14] R. Masa'deh et al., The impact of knowledge management on job performance in higher education: The case of the University of Jordan, Journal of Enterprise Information Management. 30(2) (2017) 244-262. 